\title{
EXPERIMENTAL INVESTIGATION OF MECHANICAL CHARACTERISTICS AND VIBRATION ANALYSIS OF BANANA FIBER REINFORCED COMPOSITES
}

\author{
Naveen $\mathbf{P ~ G}^{1}$, Ravindra Babu $\mathbf{G}^{2}$ \\ ${ }^{1}$ Student, M Tech, Mechanical Machine Design, SCEM, Adyar, Mangalore, Karnataka, India \\ ${ }^{2}$ Assistant Professor, Department of Mechanical Engineering, SCEM, Adyar, Mangalore, Karnataka, India
}

\begin{abstract}
In the current scenario, the concern of global warming and the environmental pollution has led the scientists to search for alternative materials that can be used in various engineering applications. For this purpose, natural fibers can be used due to their low density, low cost and bio-degradability. In the present work, banana fiber is utilized as a reinforcing material and epoxy as matrix material to prepare the composite samples. The composite samples of different fiber/epoxy ratios are prepared by hand lay-up technique. Various mechanical tests such as tensile, flexural and compression tests are performed on the fabricated composite samples. Vibration characteristics such as natural frequency, damping factor and logarithmic decrement are found by FFT Test. The obtained value of natural frequency is compared with the analytical value as determined using NX Nastran. Thus depending on the obtained values, best suited fiber/epoxy ratio is chosen.
\end{abstract}

Keywords: Composites, Banana Fiber, Mechanical Characteristics, Vibration Analysis etc...

\section{INTRODUCTION}

A composite material is defined as a combination of two or more completely dissimilar materials with significantly different chemical and physical characteristics, which when combined form a single material with superior properties compared to the properties of the individual components. The individual materials that form a composite are known as constituents. The utilization of composites is increasing in a rapid manner mainly due to ease of production and good mechanical properties compared to that of conventional materials. Composite products range from sporting goods to components of the space shuttle.

Usually a composite is made up of two constituent materials, reinforcement and a matrix. The reinforcement provides strength and stiffness. Typically the reinforcement is stiffer, stronger and harder than the matrix. In general, reinforcement can be in the form of fiber or a particulate. The matrix is in continuous phase, which is a polymer, metal or ceramic. The matrix binds the reinforcement and helps to transfer the load among the reinforcement and also protects the reinforcement from environmental effects.

\subsection{Natural Fibers}

Over a past few years, the interest in using natural fibers like banana, bamboo, hemp, coir etc. is being increased significantly. In many structural applications, these natural fibers are being used as a substitute to glass fibers as reinforcement. Natural fibers possess several benefits over artificial glass fibers such as easy and cheaper availability, low density, renewable, recyclable and bio-degradable. Banana is considered as a fruit and fodder crop. It belongs to a Musaceae family. These fibers are bast fibers extracted from the skin covering the stem of the plant. Nowadays, these fibers are gaining a lot of importance as a source of fibers.

Banana plant is considered as a high herb which can grow up to 15 feet height. The time period between planting and harvesting a banana bunch usually varies from 9 to 12 months. The main advantage of banana plant is that it can be cultivated throughout the year. Banana plants are grown in tropical areas where the average rainfall per year is 200 centimeters and average temperature is $27^{\circ} \mathrm{C}$. In general, banana cultivation is a labor intensive because it requires individual care in order to obtain quality fruit. After the fruit production, the stem of the banana plant is thrown as agricultural waste product to a great extent. Instead of throwing this pseudo-stem as a waste, these can be effectively utilized in the production of fibers which can be used in many fields. All varieties of banana plants are rich in fibers. Each and every part of banana plant has fibers of various colors, staple length and strength which can be used for different applications. In addition to fruit production, the leftover products such as pseudo stem, leaves, suckers etc. can be used as a biomass.

Dieter H Mueller and Andreas Krobjilowski [1] reported that substitution of synthetic fibers by natural fibers such as cotton, hemp, flax etc. reduces the component's weight and also improves the mechanical properties. These natural fiber reinforced composites can be effectively used in automotive industries and in structural components. Geethamma et al [2] stated that composite materials can be suitably used in the field of packing, aerospace, construction, sport and 
automotive industries. By using natural fiber as reinforcement, the weight can be reduced by $10 \%$ and energy required for production can be reduced by $80 \%$. Also it is reported that the cost of the component can be reduced by $5 \%$ compared to that of fiber glass-reinforced components. Maleque et al [3] studied the mechanical behavior of pseudo-stem banana fiber reinforced composites. The tensile strength of banana fiber reinforced composite increases by $90 \%$ compared to that of pure epoxy. Ashish Khandelwal et al [4] conducted experiment on short fiber fabricated composites to determine the mechanical behavior. A comparative study is made on synthetic fiber reinforced composites and banana fiber reinforced composites. The composites are prepared by hand-lay-up method. It is found that the composites exhibits improved tensile, compressive, flexural and micro hardness compared to that of pure epoxy. Also it is finally concluded that synthetic fiber can be replaced by banana fiber which is a natural fiber. K Senthil Kumar et al [5] conducted research work on damping response of natural fiber reinforced composites. The fiber content with $50 \%$ weight fraction gives maximum mechanical strength and also free vibration properties. The maximum natural frequency is obtained for $4 \mathrm{~mm} / 50 \%$ weight of banana fiber reinforced composites and $5 \mathrm{~mm} / 50 \%$ weight sisal fiber reinforced composites in all the three modes.

\section{MATERIALS AND FABRICATION}

\subsection{Reinforcement Material}

Banana fiber is employed as a reinforcement material for the fabrication of the composites. Mature pseudo stem was collected from the farm and the fibers were extracted from the stem. For the present work, the outer and middle sheaths of the pseudo stem of banana fibers are used. Fibers can be extracted manually, chemically or mechanically. Here the fibers are extracted manually. The extracted fibers are then washed cleanly in water to eliminate dirt and other foreign particles and then kept in sunlight up to 24 hours to remove free water. These fibers are then chopped into small pieces of about $0.5 \mathrm{~cm}$ length and width.

From the literature analysis, it is observed that a particular size of banana fibers possess superior properties compared to other mesh sizes. For the differentiation of these chopped fibers in numerous mesh sizes, a sieve shaker machine is used. The machine is run for around 20 minutes for differentiating the fibers. Thus various mesh size ranging between 850 microns and 212 microns are obtained. With the use of fibers of one particular grain size, the specimen may exhibit high amount of porosity. In order to reduce this problem, smaller grain size particles are mixed with the higher mesh sized particle in a definite proportion.

\subsection{Matrix Material}

Epoxy resin is utilized as a matrix material for the preparation of the composites. Epoxy has many advantages such as high toughness, good resistance to temperature etc. The epoxy resin used for the present study is LAPOX L12. The hardener LAPOX K6 is used in order to accelerate the curing of resin at room temperature. The hardener K6 has low viscosity and short pot life. The hardener K6 has got very good curing property at room temperature. The epoxy is mixed along with the hardener in the ratio 10:1.

\subsection{Fabrication of Molds}

The composite test specimens must be prepared as per standard dimensions for appropriate tests. So it is necessary to fabricate molds of different dimensions as required for various tests. A rectangular Teflon plate is used for the fabrication of molds. In order to achieve good results, molds are fabricated as per ASTM standards. The standard dimensions may vary for different tests. Teflon material is chosen as a mold material. . The cavities for various test specimens are engraved by using milling and drilling machine.

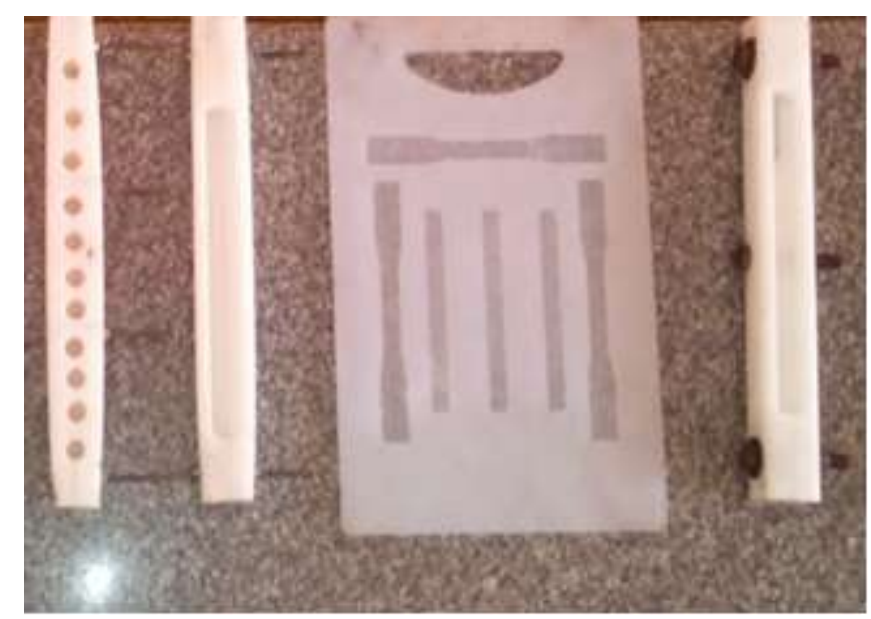

Fig -1: Molds fabricated for preparing the composite specimens

\subsection{Preparation of Composite Mixture}

The composite mixture is prepared depending on the weight fraction, which is determined based on the volume of the composite material. On estimation of required percentage weight fraction of banana fibers, the required percentage of epoxy resin is found. Based on the literature review, the mixing proportion of banana fibers and epoxy is obtained. The banana fibers of required grain sizes are weighed and are kept in a bowl.

The epoxy resin used is Lapox-L12 and the hardener used is K6. By using a measuring jar, the required volume of the epoxy and hardener is measured. The epoxy and hardener are mixed in the ratio 10:1 in a separate bowl. This mixture is stirred gently for about a minute. Then the weighed banana fibers are added into the mixture. This mixture is then stirred for about 15 minutes. Usually the gel time ranges from 15 to 20 minutes. In order to get better homogeneity and wettability, the mixture must be poured into the respective molds before gel time. 


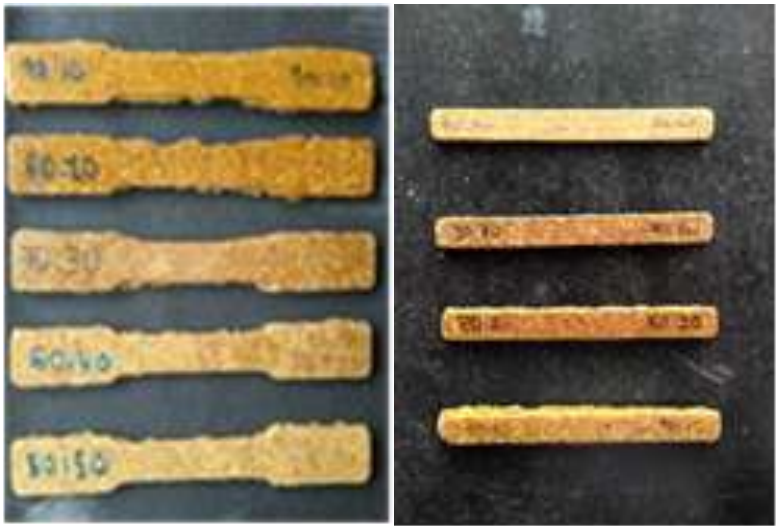

Fig -2 Banana Fiber Reinforced Epoxy Composite (a) Tensile specimen (b) Flexural specimen

\section{EXPERIMENTATION}

The main objective of the present study is to analyze the mechanical characteristics and dynamic behavior of the composite test specimens.

\subsection{Tensile Test}

The tensile test specimens were fabricated according to the dimensions of ASTM D638. The test is carried out at Advanced Composite Material Testing lab at MIT, Manipal on a Universal Testing machine of FIE make UNITEK 9450 with a $50 \mathrm{kN}$ load capacity. A microprocessor based system interfaced with UTM is used for data acquisition and storage of data. The length of the specimen is $165 \mathrm{~mm}$ and gauge length is $57 \mathrm{~mm}$. The test specimen is clamped between the two fixtures. The strain rate is fixed at $2 \mathrm{~mm} / \mathrm{min}$. A continuous progressive load is applied on the specimen until fracture occurs. The results are stored in the software. The elastic modulus, maximum stress and break elongation percentage of various specimens are determined. In order to get accurate results, the test is performed on three specimens and the average is taken.

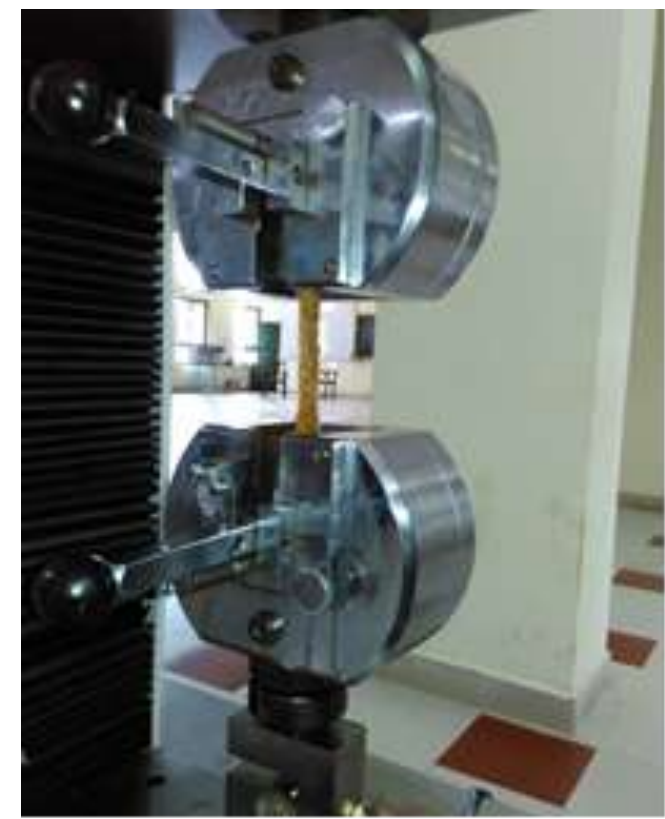

Fig -3: Tensile test fixture

\subsection{Flexural Test}

The flexural test specimens were fabricated according to the dimension of ASTM D790. The flexural test is carried out at Advanced Composite Material Testing lab at MIT, Manipal on a Universal Testing machine of $50 \mathrm{kN}$ load capacity of FIE make UNITEK 9450. A microprocessor based system interfaced with UTM is used for data acquisition and storage of data. The span length of the bottom fixture is set as 72 $\mathrm{mm}$. A 3 point contact flexural fixture is used for the purpose of testing the specimen. The strain rate is fixed at $2 \mathrm{~mm} / \mathrm{min}$. A continuous progressive load is applied on the specimen until fracture occurs. The results are stored in the software. The flexural strength, flexural modulus and break elongation percentage of various specimens are found. In order to get accurate results, the test is performed on three specimens and the average is taken.

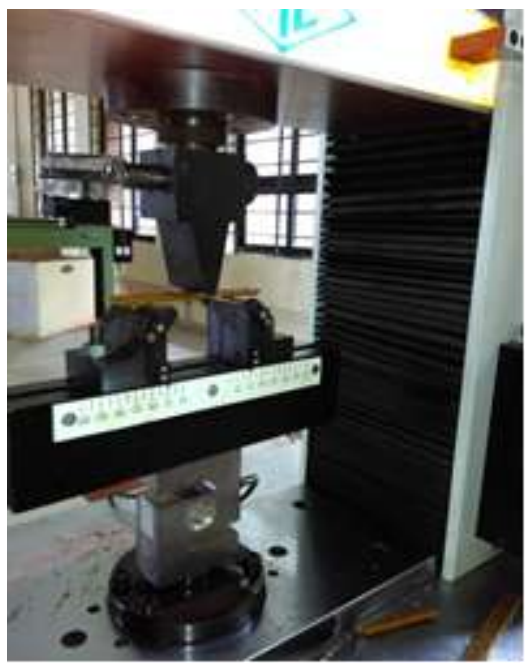

Fig -4: Flexural test fixture

\subsection{Compression Test}

The compression test specimens were made as per ASTM D695 standard. The diameter of the specimen as per the standard is $12.7 \mathrm{~mm}$ and height is $25.4 \mathrm{~mm}$. The length to diameter ratio is 2 . The compression test is carried out at Advanced Composite Material Testing lab at MIT, Manipal on a Universal Testing machine of FIE Make UNITEK 9450 make with a $50 \mathrm{kN}$ load. A microprocessor based system interfaced with UTM is used for data acquisition and storage of data. The speed of the test is fixed to $0.5 \mathrm{~mm} / \mathrm{min}$. The test specimen is placed between two flat compression fixtures and a gradual load is applied on it. The progressive load is applied until fracture occurs and the results are stored in the computer. In order to get accurate results, the test is performed on three specimens and average is taken. 


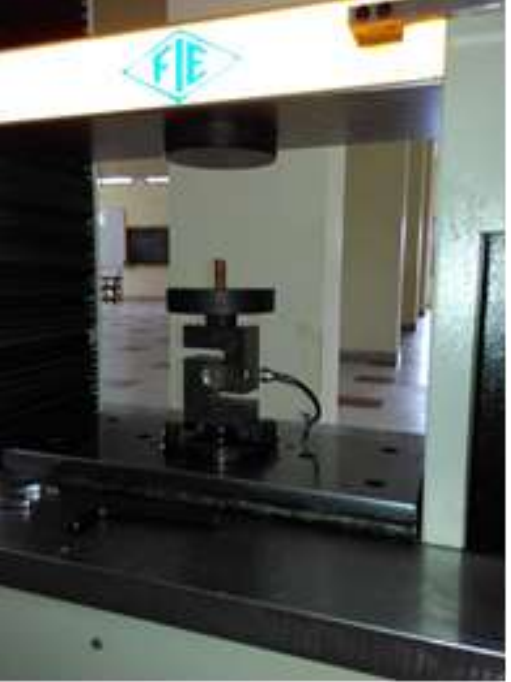

Fig -5: Compresssion test fixture

\subsection{Damping Test}

The damping specimens were prepared as per the requirements at the test center. The specimen is fixed at one end and an accelerometer of KISTLER company make is fixed at the other end with the help of wax. This forms like a cantilever beam. Accelerometer is connected to a Data Acquisition System which in turn is connected to a computer interface which helps in storing the data. The LAB VIEW software is used to process the data and plot the magnitude versus frequency response curve. An impact hammer is used to knock the specimen and the vibration response is obtained. Thus the natural frequency of the specimen can be obtained. The dimensions of composite material for FFT test is 200 $\mathrm{mm} \times 20 \mathrm{~mm} \times 3 \mathrm{~mm}$. The effective length of the composite specimen is $180 \mathrm{~mm}$ and $20 \mathrm{~mm}$ of composite plate specimen is fixed at one end. The half-power band width method was employed to find the damping coefficient values of composites through Frequency Response Functions (FRF) curves obtained from the FFT analyzer.

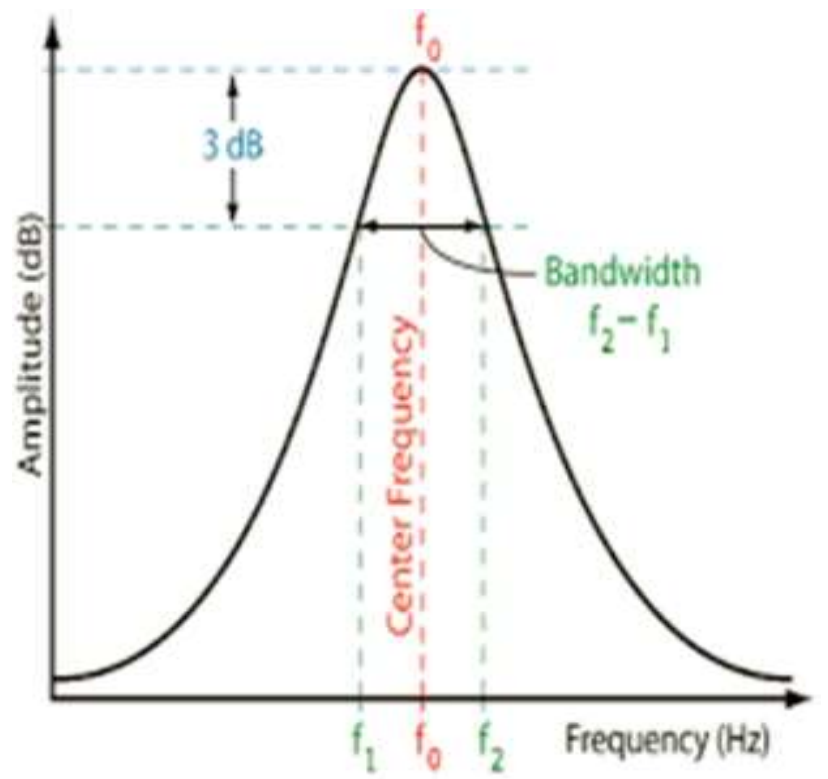

Fig -6: Bandwidth Method of Damping Measurement

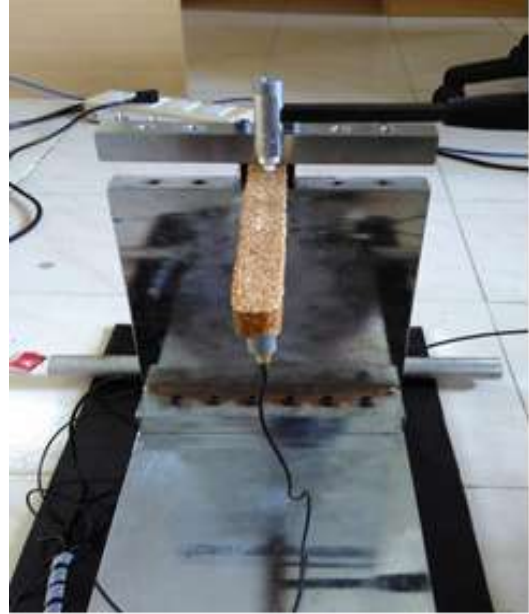

Fig -7: Damping Test Setup

\section{RESULTS AND DISCUSSIONS}

\subsection{Tensile Test Results}

Table -1: Result of tensile test

\begin{tabular}{|l|l|l|l|}
\hline $\begin{array}{l}\text { Fiber } \\
\text { Weight } \\
(\%)\end{array}$ & $\begin{array}{l}\text { Epoxy } \\
\text { Weight } \\
(\%)\end{array}$ & $\begin{array}{l}\text { Tensile } \\
\text { Strength } \\
(\mathbf{M P a}\end{array}$ & $\begin{array}{l}\text { Modulus } \\
\text { of } \\
\text { Elasticity } \\
(\mathbf{G P a})\end{array}$ \\
\hline 50 & 50 & 5.51 & 0.1826 \\
\hline 40 & 60 & 8.66 & 0.204 \\
\hline 30 & 70 & 11.54 & 0.242 \\
\hline 20 & 80 & 22.18 & 0.319 \\
\hline 10 & 90 & 24.94 & 0.448 \\
\hline
\end{tabular}

The tensile strength, modulus of elasticity and extension at maximum stress for all specimens are recorded and are tabulated in the table 1 . It is found that the tensile strength increases with the increase in the epoxy content and attains a peak value for $10 \%$ fiber and $90 \%$ epoxy content composite specimen. It is also found that the modulus of elasticity increases as epoxy composition increases and reaches a maximum value of $0.448 \mathrm{GPa}$. The characteristic curve of tensile strength and modulus of elasticity are shown in the fig 8 and fig 9 respectively.

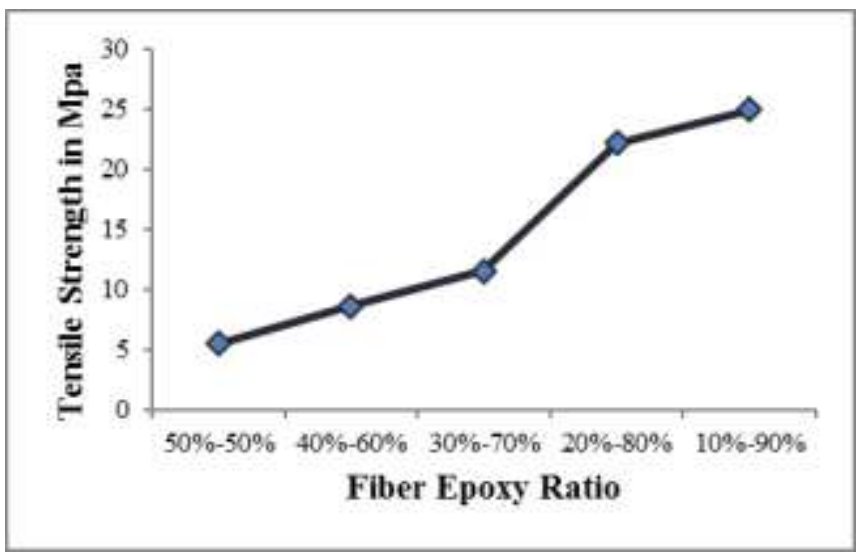

Fig -8: Tensile strength vs Fiber Epoxy Ratio 


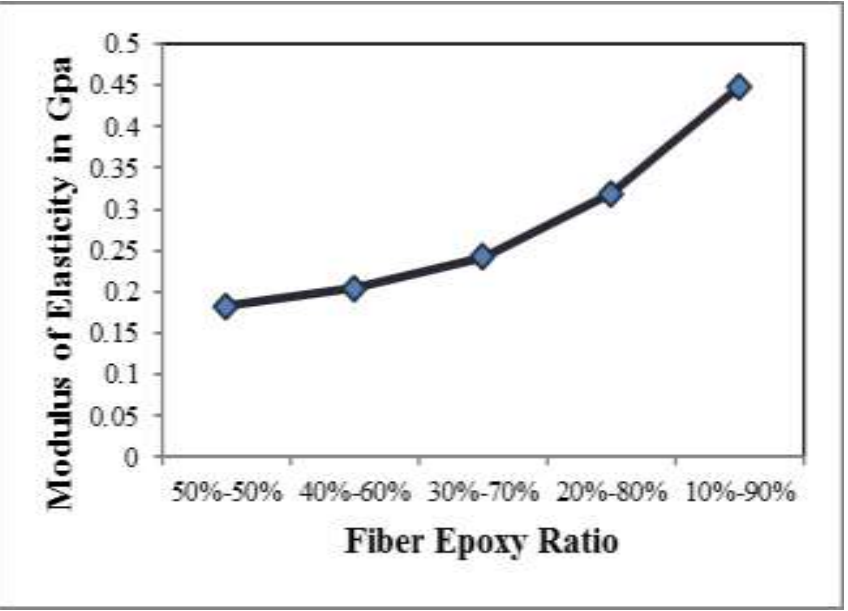

Fig -9: Youngs Modulus vs Fiber Epoxy Ratio

\subsection{Flexural Test Results}

Table -2: Result of flexural test

\begin{tabular}{|l|l|l|l|}
\hline $\begin{array}{l}\text { Fiber } \\
\text { Weight } \\
(\%)\end{array}$ & $\begin{array}{l}\text { Epoxy } \\
\text { Weight } \\
(\%)\end{array}$ & $\begin{array}{l}\text { Flexural } \\
\text { Strength } \\
(\mathbf{M P a})\end{array}$ & $\begin{array}{l}\text { Flexural } \\
\text { Modulus } \\
(\mathbf{G P a})\end{array}$ \\
\hline 50 & 50 & 9.45 & 1.91 \\
\hline 40 & 60 & 23.63 & 4.89 \\
\hline 30 & 70 & 37.8 & 6.95 \\
\hline 20 & 80 & 56.7 & 7.34 \\
\hline 10 & 90 & 42.53 & 8.71 \\
\hline
\end{tabular}

The flexural strength, flexural modulus and extension at maximum stress for all specimens are recorded and are tabulated in the table 2 . It is found that initially the flexural strength increases with the epoxy content. It attains a maximum value for $20 \%$ fiber and $80 \%$ epoxy content specimen. It is also found that the flexural modulus increases with the epoxy content. The characteristic curve of flexural strength and flexural modulus are presented in the fig 10 and fig 11 respectively.

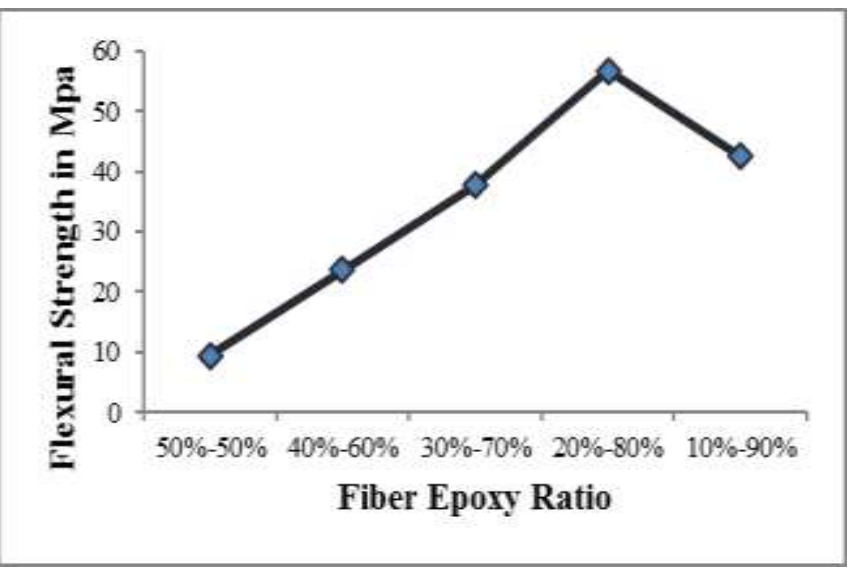

Fig -10: Flexural Strength vs Fiber Epoxy Ratio

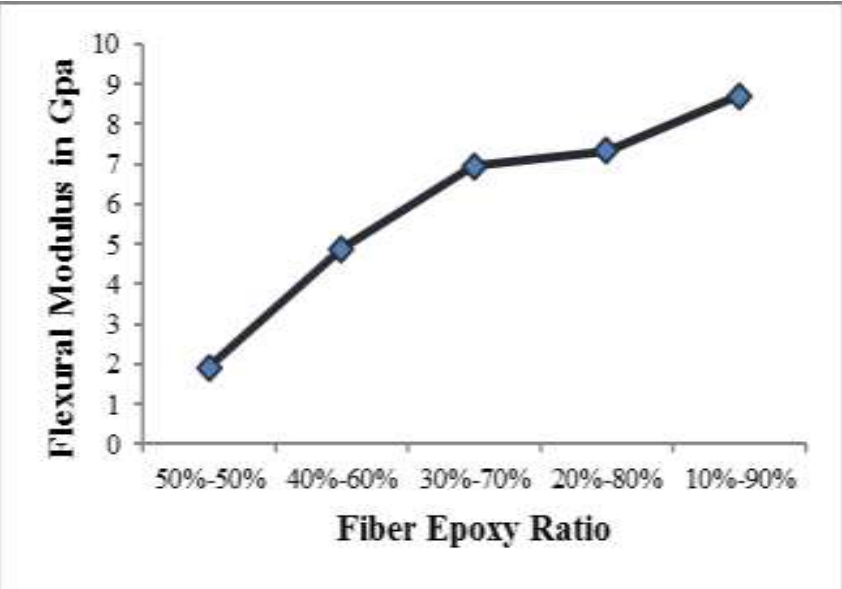

Fig -11: Flexural Modulus vs Fiber Epoxy Ratio

\subsection{Compression Test Results}

Table -3: Result of compression test

\begin{tabular}{|l|l|l|}
\hline $\begin{array}{l}\text { Fiber } \\
\text { Weight } \\
(\%)\end{array}$ & $\begin{array}{l}\text { Epoxy } \\
\text { Weight } \\
(\boldsymbol{\%})\end{array}$ & $\begin{array}{l}\text { Compression } \\
\text { Strength } \\
(\mathbf{M P a})\end{array}$ \\
\hline 50 & 50 & 21 \\
\hline 40 & 60 & 40 \\
\hline 30 & 70 & 62 \\
\hline 20 & 80 & 76 \\
\hline 10 & 90 & 66 \\
\hline
\end{tabular}

The compressive strength for all specimens are recorded is tabulated in table 3 . The maximum compressive strength obtained is $76 \mathrm{MPa}$ for $20 \%$ fiber and $80 \%$ epoxy content composite specimen. The characteristic curve of compressive strength is shown in the fig 12 .

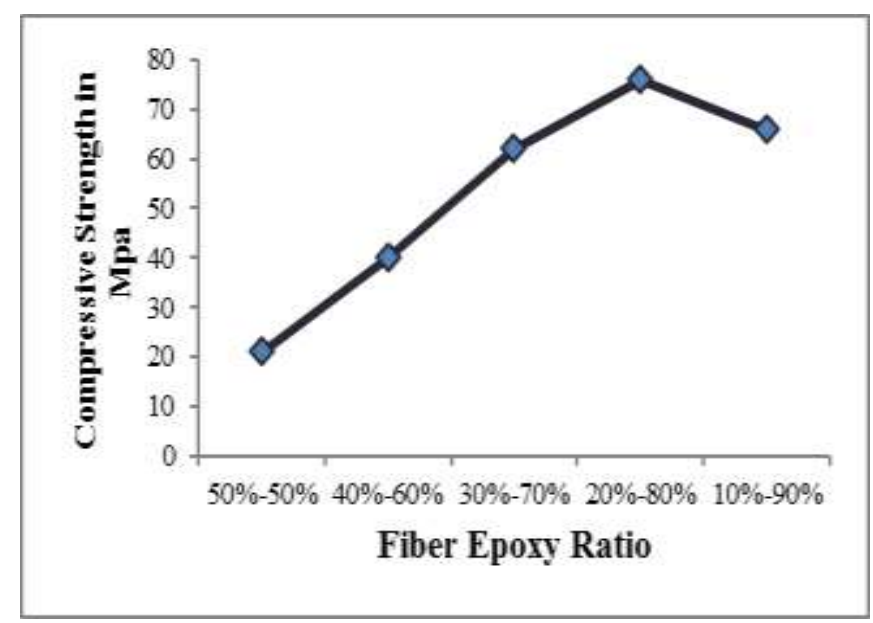

Fig -12: Fiber Epoxy Ratio vs Compressive Strength

\subsection{Damping Test Results}

The fundamental frequencies of the specimen are obtained from FFT test. Using half-power bandwidth method, the damping factor and logarithmic decrement are computed and are represented in the table below. 
Table -4: Damping Test Results

\begin{tabular}{|l|l|l|l|l|}
\hline $\begin{array}{l}\text { Fiber } \\
\text { Weigh } \\
\mathbf{t} \\
(\boldsymbol{\%})\end{array}$ & $\begin{array}{l}\text { Epoxy } \\
\text { Weigh } \\
\mathbf{t} \\
(\boldsymbol{\%})\end{array}$ & $\begin{array}{l}\text { Fundament } \\
\text { al } \\
\text { Frequency } \\
\text { fn (Hz) }\end{array}$ & $\begin{array}{l}\text { Dampin } \\
\text { g Ratio } \\
\zeta\end{array}$ & $\begin{array}{l}\text { Logarithmi } \\
\mathbf{c} \\
\text { Decrement } \\
\boldsymbol{\delta}\end{array}$ \\
\hline 40 & 60 & 80.896 & 0.0441 & 0.2774 \\
\hline 30 & 70 & 96.256 & 0.0386 & 0.2429 \\
\hline 20 & 80 & 101.888 & 0.0287 & 0.1804 \\
\hline 10 & 90 & 110.592 & 0.0212 & 0.1332 \\
\hline
\end{tabular}

From the table, it is clear that maximum damping value is obtained for $40 \%$ fiber and $60 \%$ epoxy content composite specimen. Hence this ratio exhibits better damping property. As the epoxy content increases the damping value decreases. The logarithmic decrement value also decreases with increase in epoxy content. The characteristic curve of damping factor and logarithmic decrement, the frequency response curve of the specimens are shown in the figure below.

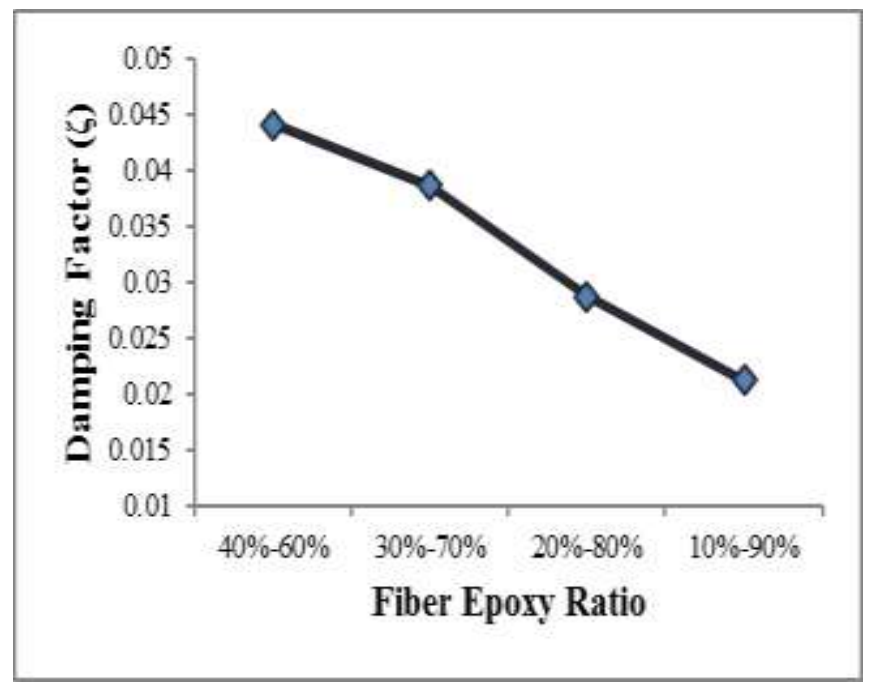

Fig -13: Damping factor vs Fiber epoxy ratio

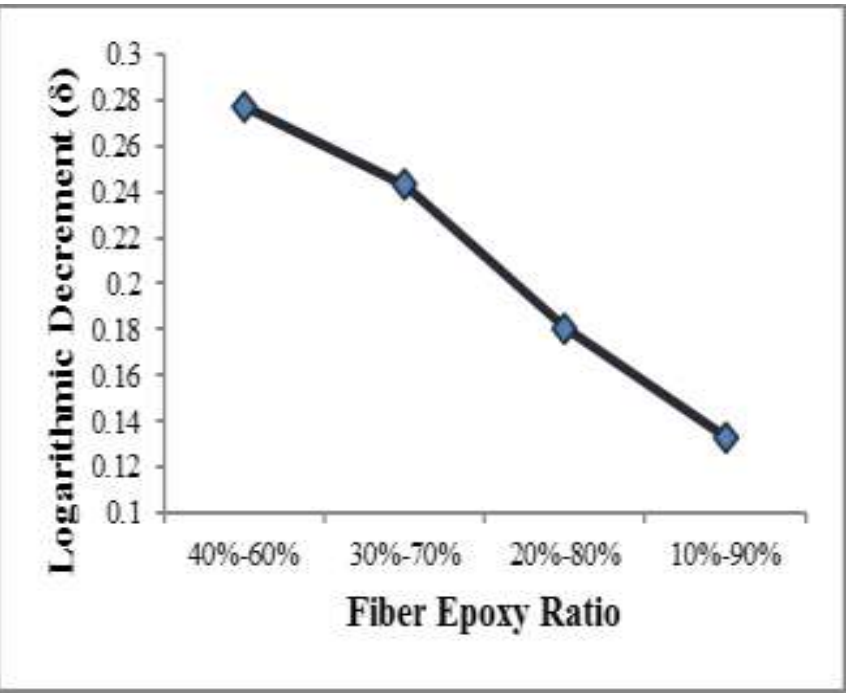

Fig -14: Logarithmic Decrement vs Fiber epoxy ratio

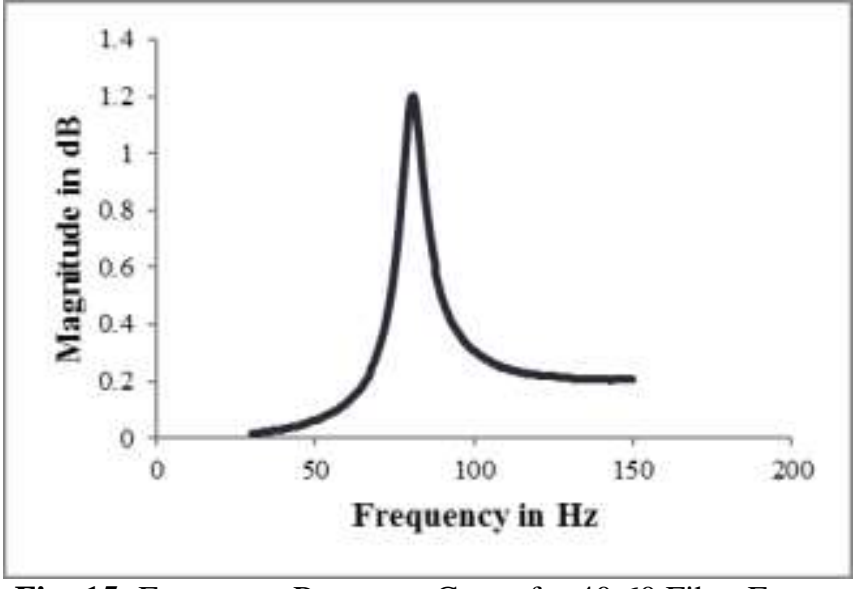

Fig -15: Frequency Response Curve for 40:60 Fiber Epoxy Ratio

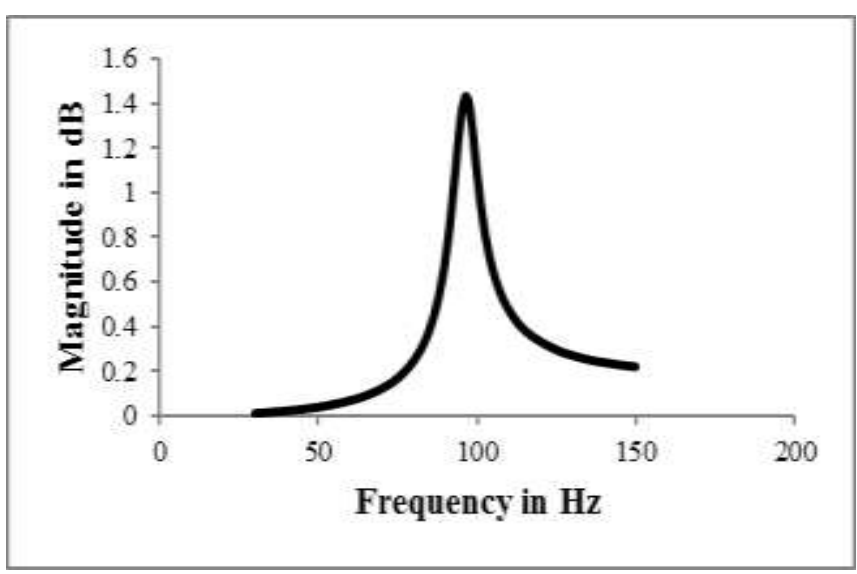

Fig -16: Frequency Response Curve for 30:70 Fiber Epoxy Ratio

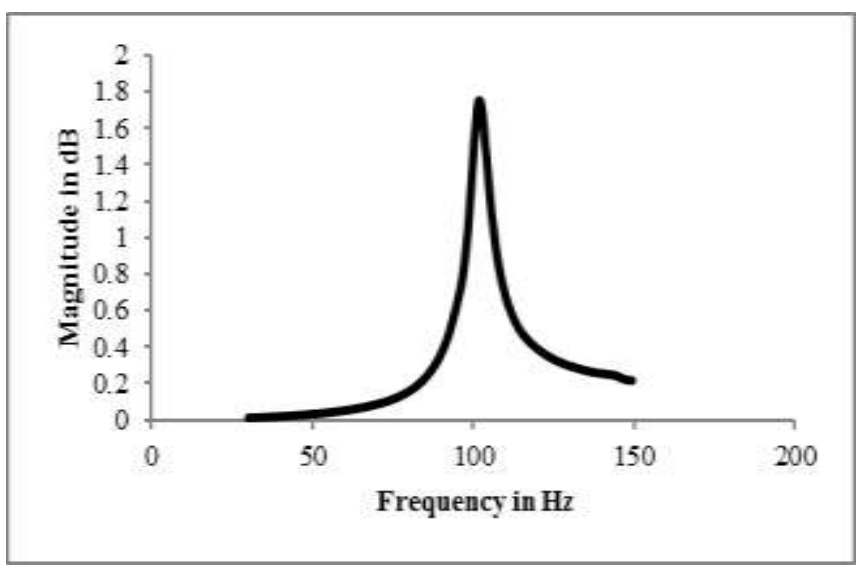

Fig -17: Frequency Response Curve for 20:80 Fiber Epoxy Ratio

\section{FINITE ELEMENT ANALYSIS USING NX NASTRAN}

\subsection{Modal Analysis}

Modal analysis is a methodology which helps in studying the dynamic characteristics of the composite specimen. This analysis is performed to determine the natural characteristics such as fundamental frequency and mode shapes of the 
composite specimen. Natural frequency is found for first mode shape of each of the composite specimen and the corresponding modal behavior is shown in the figure below.

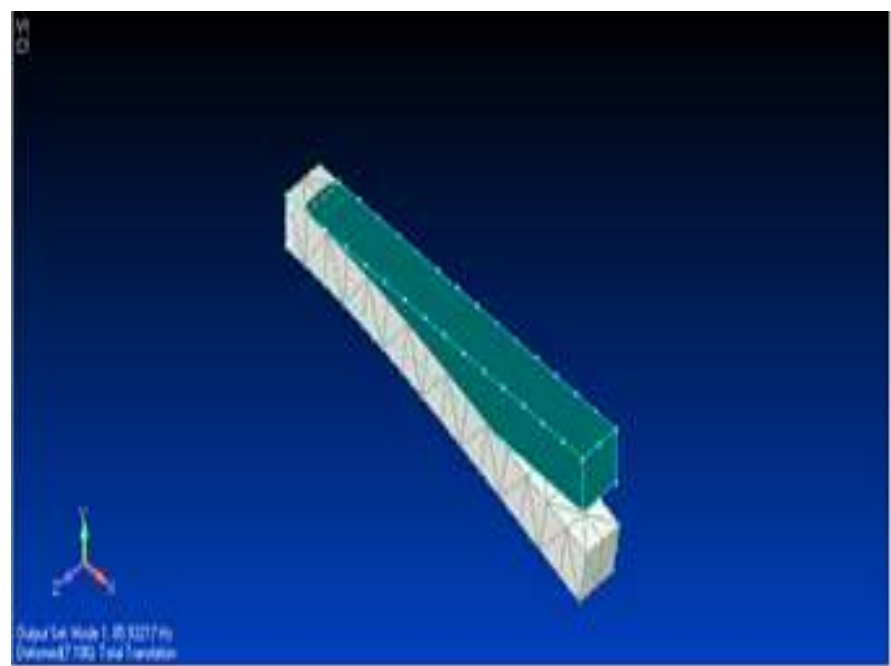

Fig -18: Mode 1 shape of $40 \%$ Fiber and 60\% Epoxy Composite Specimen

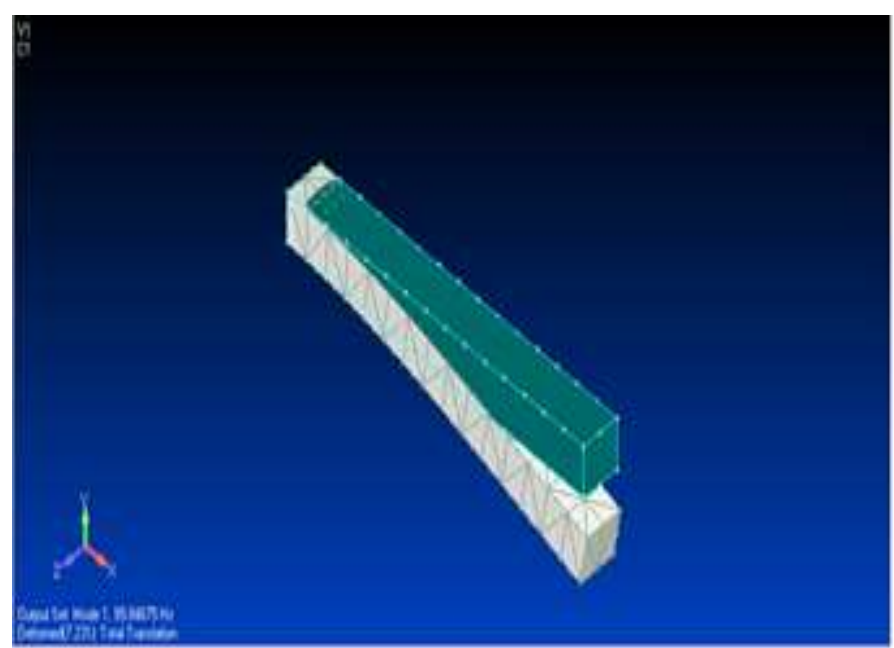

Fig -19: Mode 1 shape of $30 \%$ Fiber and 70\% Epoxy Composite Specimen

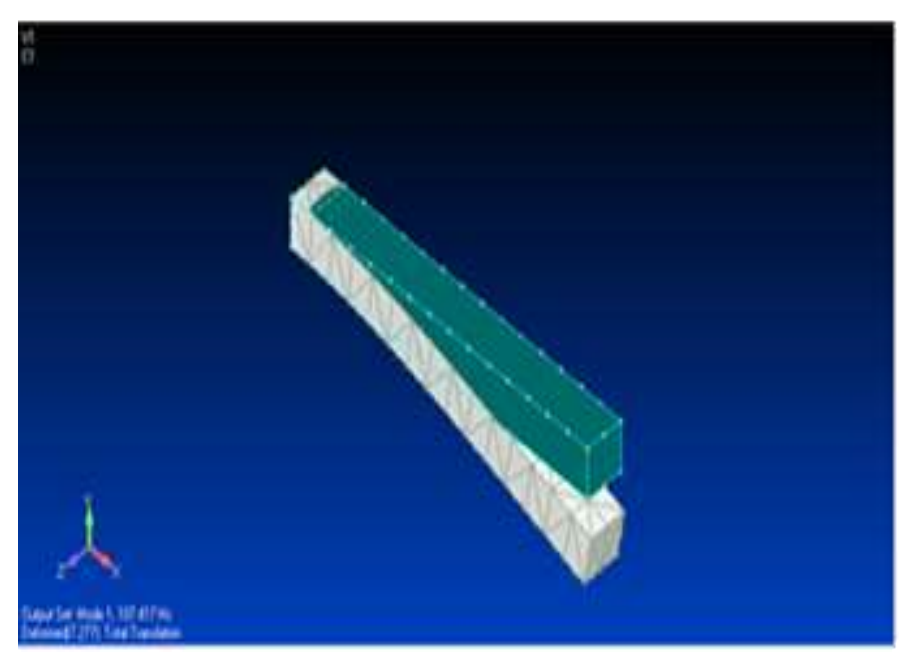

Fig -20: Mode 1 shape of $20 \%$ Fiber and 80\% Epoxy Composite Specimen

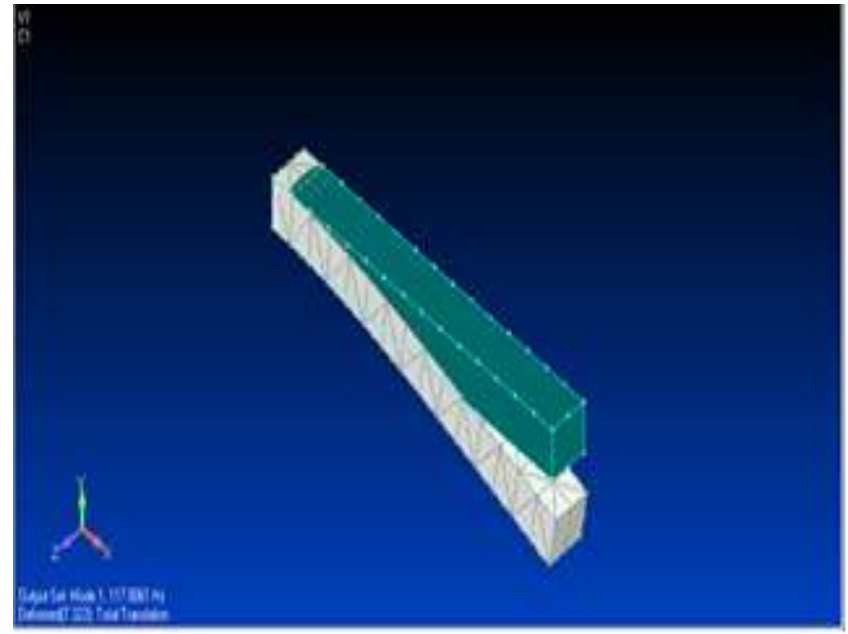

Fig -21: Mode 1 shape of $10 \%$ Fiber and 90\% Epoxy Composite Specimen

\subsection{Comparison of Experimental Values of Natural}

\section{Frequency with that of Analytical Values}

The values of natural frequencies for first mode obtained experimentally are compared with that of analytical values for all fiber epoxy compositions. These values are represented in the table below.

Table -4: Comparison of experimental and analytical natural

\begin{tabular}{|l|l|l|l|}
\hline $\begin{array}{l}\text { Fiber } \\
\text { Epoxy } \\
\text { Ratio }\end{array}$ & \multicolumn{2}{|c|}{$\begin{array}{l}\text { Frequency for Mode 1 (fn) } \\
\text { in Hz }\end{array}$} & $\begin{array}{l}\text { Percentage } \\
\text { Deviation } \\
(\%)\end{array}$ \\
\cline { 2 - 4 } & Experimental & Analytical & \\
\hline $40: 60$ & 80.89 & 85.93 & 6.23 \\
\hline $30: 70$ & 96.26 & 99.85 & 3.73 \\
\hline $20: 80$ & 101.89 & 107.42 & 5.43 \\
\hline $10: 90$ & 110.59 & 117.81 & 6.53 \\
\hline
\end{tabular}

From the above table, it is found that the experimental values are very close to the analytical values as determined using NX Nastran. Hence these values can be directly considered to find the damping behavior of the composite specimen.

\section{CONCLUSIONS $\backslash$}

$>$ From tensile test it can be observed that the tensile strength of the banana fiber reinforced composite specimen increases with the increase in epoxy content. The maximum value obtained is $24.94 \mathrm{MPa}$ for $10 \%$ 90\% Fiber Epoxy composition. Also the Young's modulus increases with the increase in epoxy content.

$>$ From flexural test it is observed that the flexural strength of the banana fiber reinforced composite specimen increases with the increase in epoxy content and it attains a maximum value of $56.7 \mathrm{MPa}$ for $20 \%-80 \%$ Fiber Epoxy composition.

$>$ From compression test can be inferred that the maximum compressive strength obtained is $76 \mathrm{MPa}$ for 20\%-80\% Fiber Epoxy composition. 
$>$ Therefore from all the three tests, it can be concluded that 20\%-80\% Fiber Epoxy composition is the best ratio. This may be due to the fact that for this ratio, there is a strong interaction between the fiber and epoxy. Thus this ratio can be used to prepare the composites which are suitable for medium strength applications.

$>$ From FFT Test it is clear that maximum damping value is obtained for $40 \%-60 \%$ Fiber Epoxy content composite specimen. Hence this ratio exhibits better damping property. As the epoxy content increases the damping value decreases. The logarithmic decrement value also decreases with the increase in epoxy content.

$>$ It is found that the experimental values of natural frequencies of the banana fiber reinforced composites are in close agreement with that of the analytical values determined using NX Nastran.

\section{ACKNOWLEDGEMENT}

The authors wish to thank the following people for providing the opportunities to use their equipment for the experimental work:

i. Dr. Dayanand Pai, Professor, Department of Aeronautical and Automobile Engineering, MIT, Manipal for allowing to conduct the experimental tests at Advance Composite Testing Lab, MIT, Manipal.

ii. Dr. Ganghadharan, Professor and Head, Department of Mechanical Engineering, NITK, Surathkal, for allowing to conduct the experimental tests at SOLVE Lab, NITK.

iii. Management of Sahyadri College of Engineering and Management, Mangalore for providing all the facilities for the project work.

\section{REFERENCES}

[1]. Dieter H Mueller and Andreas Krobjilowski, "New Discovery in the Properties of Composites Reinforced with Natural Fibers", Journal of Industrial Textiles, Vol. 33, No. 2, October 2003.

[2]. Geethamma V G, Thomas Mathew, K. Lakshminarayanan, R Sabu Thomas "Composite of short coir fibres and natural rubber effect of chemical modification, loading and orientation of fibre", 1998.

[3]. Maleque M. A., Belal F. Y., Sapuan S. M., "Mechanical Properties Study of Pseudo-Stem Banana Fiber Reinforced Epoxy Composite", The Arabian Journal for Science and Engineering, 32 (2007), pp. 359-364.

[4]. Ashish Khandelwal and Abhishek Choubey, "Mechanical And Tribological Characterization of Short Fibers Reinforced Polymer Composites", IOSR Journal of Engineering, ISSN: 2278-8719, Vol. 04, Issue 04 (April. 2014).

[5]. K. Senthil Kumar, I. Siva, P. Jeyaraj, J.T. Winowlin Jappes, S.C. Amico and N. Rajini, "Synergy of fiber length and content on free vibration and damping behavior of natural fiber reinforced polyester composite beams" Materials and Design 56 (2014), pp.379-386.

[6]. Authar K.Kaw, "Mechanics of Composite Materials", Second Edition, Taylor and Francis, 2006.

[7]. G.K.Grover, "Mechanical Vibrations", Eighth edition, NEM CHAND AND BROS, 2009.

\section{BIOGRAPHIES}

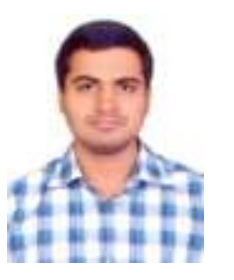

Naveen $\mathbf{P}$ G is currently doing M.tech (Machine Design) in Sahyadri College of Engineering and Management. He received BE degree from National Institute of Engineering, Mysore.

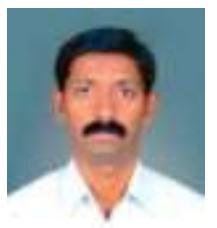

Ravindra Babu G is working in Sahyadri College of Engineering and Management as an Assistant Professor in the department of Mechanical engineering. He received M.Tech in Machine Design degree from BIET Davangere affiliated to VTU and BE degree in Industrial Production from SJMIT, Chitradurga. He has published 1 National and 2 International Conference papers in the field of composites. 